\title{
Thiomicrorhabdus immobilis sp. nov., a mesophilic sulfuroxidizing bacterium isolated from sediment of a brackish lake
}

Hisaya Kojima ( $\sim$ kojimah@lowtem.hokudai.ac.jp )

Hokkaido University: Hokkaido Daigaku https://orcid.org/0000-0003-3750-8353

Jun Mochizuki

Hokkaido University: Hokkaido Daigaku

Mamoru Kanda

Hokkaido University: Hokkaido Daigaku

Tomohiro Watanabe

Hokkaido University: Hokkaido Daigaku

Manabu Fukui

Hokkaido University: Hokkaido Daigaku

Research Article

Keywords:

Posted Date: January 21st, 2022

DOI: https://doi.org/10.21203/rs.3.rs-1272781/v1

License: (c) (1) This work is licensed under a Creative Commons Attribution 4.0 International License.

Read Full License 
2 Thiomicrorhabdus immobilis sp. nov., a mesophilic sulfur3 oxidizing bacterium isolated from sediment of a brackish lake

$5 \quad$ Hisaya Kojima $^{1 *}$, Jun Mochizuki ${ }^{1,2}$, Mamoru Kanda ${ }^{1,2}$, Tomohiro Watanabe ${ }^{1}$ and Manabu Fukui ${ }^{1}$

7

8 1. The Institute of Low Temperature Science, Hokkaido University. Kita-19, Nishi-8, 9 Kita-ku, Sapporo 060-0819, Japan

10 2. Graduate School of Environmental Science, Hokkaido University, Kita-10, Nishi-5, 11 Kita-ku, Sapporo 060-0810, Japan

$13 *$ Corresponding author

14 Tel/fax number: +81 117065460

$15 \quad$ E-mail: kojimah@lowtem.hokudai.ac.jp

16 The Institute of Low Temperature Science, Hokkaido University. Kita-19, Nishi-8, Kita17 ku, Sapporo 060-0819, Japan 


\section{Abstract}

A novel sulfur-oxidizing bacterium, strain $\mathrm{Am} 19^{\mathrm{T}}$, was isolated from sediment of a brackish lake. Strain Am19 ${ }^{\mathrm{T}}$ grew chemolithotrophically on inorganic sulfur compounds, and heterotrophic growth was not observed. Cells were rod-shaped with

24 length of $1.1-3.0 \mu \mathrm{m}$ and width of $0.5-0.8 \mu \mathrm{m}$. Growth was observed at $5-37^{\circ} \mathrm{C}$ with an optimum growth temperature of $30^{\circ} \mathrm{C}$. The $\mathrm{pH}$ range for growth was $5.6-8.5$ with an optimum $\mathrm{pH}$ of 6.6-7.0. Major fatty acids were summed feature $3\left(\mathrm{C}_{16}: 1 \omega 7 \mathrm{c}\right.$ and/or

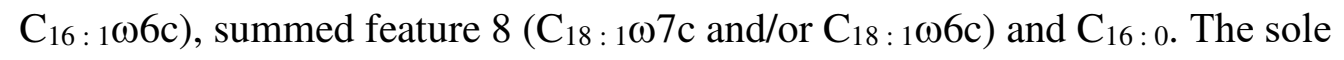
respiratory quinone was ubiquinone- 8 . The complete genome of strain $A m 19^{\mathrm{T}}$ is composed of a circular chromosome with length of $2.5 \mathrm{Mbp}$ and $\mathrm{G}+\mathrm{C}$ content of 42.7 mol\%. Phylogenetic analysis based on genomic data indicated that strain Am19 belongs to the genus Thiomicrorhabdus but is distinct from any existing species.

Analysis of the 16S rRNA gene supported creation of a new species to accommodate strain $\mathrm{Am} 19^{\mathrm{T}}$. On the basis of genomic and phenotypic characteristics, strain $\mathrm{Am} 19^{\mathrm{T}}(=$ NBRC $114602^{\mathrm{T}}=$ BCRC $81336^{\mathrm{T}}$ ) is proposed as the type strain of a new species, with name of Thiomicrorhabdus immobilis sp. nov. 


\section{Introduction}

The genus Thiomicrorhabdus was established in 2017, within the family Piscirickettsiaceae (Boden et al.2017a). Afterward, the genus description was emended in 2017 and 2021 (Boden et al., 2017b; Liu et al., 2021). In this genus, there are nine species with validly published names at present, including five species which were originally classified in another genus. The reclassified five species are T. frisia (Brinkhoff et al., 1999a), T. chilensis (Brinkhoff et al., 1999b), T. arctica, T. psychrophila (Knittel et al., 2005) and T. hydrogeniphila (Watsuji et al, 2016). The other four species described in this genus are T. aquaedulcis (Kojima \& Fukui 2019), T. indica (Liu et al., 2020), T. sediminis and T. xiamenensis (Liu et al., 2021). They are all obligate chemolithoautotrophs which oxidize sulfur compounds. They require oxygen as electron acceptor for growth, and rely on sulfur compounds as electron donor. As exceptional cases, anaerobic growth with nitrite was reported in T. sediminis, and hydrogen-dependent growth was observed in T. hydrogeniphila. As common chemotaxonomic feature, all species examined share three major fatty acids, $\mathrm{C}_{16: 1}, \mathrm{C}_{18: 1}$ and $\mathrm{C}_{16: 0 \text {. }}$

In this study, a novel aerobic and mesophilic autotroph was isolated and characterized, as a representative of a new species in the genus Thiomicrorhabdus. 
Materials and methods

57

Enrichment and isolation

Strains Am19 $19^{\mathrm{T}}$ was isolated from a sediment collected at a site $(43.05 \mathrm{~N}, 144.89 \mathrm{E})$, in

Lake Akkeshi, a brackish lake in Japan. The sediment was inoculated into a bicarbonatebuffered medium, which comprised $\left(\mathrm{l}^{-1}\right): 2.5 \mathrm{~g} \mathrm{Na}_{2} \mathrm{~S}_{2} \mathrm{O}_{3} \cdot 5 \mathrm{H}_{2} \mathrm{O}, 20 \mathrm{~g} \mathrm{NaCl}, 0.2 \mathrm{~g} \mathrm{MgCl}_{2} \cdot$ $6 \mathrm{H}_{2} \mathrm{O}, 0.1 \mathrm{~g} \mathrm{CaCl}_{2} \cdot 2 \mathrm{H}_{2} \mathrm{O}, 0.1 \mathrm{~g} \mathrm{NH}_{4} \mathrm{Cl}, 0.1 \mathrm{~g} \mathrm{KH}_{2} \mathrm{PO}_{4}, 0.1 \mathrm{~g} \mathrm{KCl}, 1 \mathrm{ml}$ trace element solution, $1 \mathrm{ml}$ selenite-tungstate solution, $1 \mathrm{ml}$ vitamin mixture solution, $30 \mathrm{ml} \mathrm{NaHCO} 3$

64 solution. The medium and respective stock solutions were prepared as described previously (Kojima et al. 2016). After some transfers to medium of the same composition,

66 the composition of the medium was changed to contain $5 \mathrm{~g} \mathrm{Na}_{2} \mathrm{~S}_{2} \mathrm{O}_{3} \cdot 5 \mathrm{H}_{2} \mathrm{O}, 20 \mathrm{~g} \mathrm{NaCl}$,

$673 \mathrm{~g} \mathrm{MgCl}_{2} \cdot 6 \mathrm{H}_{2} \mathrm{O}$, and $0.3 \mathrm{~g} \mathrm{MgSO}_{4} \cdot 7 \mathrm{H}_{2} \mathrm{O}$. The other components were same as the 68 medium used to establish the first enrichment. This medium containing $\mathrm{MgSO}_{4}$ is 69 hereafter referred to as the basal medium. Strain $A m 19^{\mathrm{T}}$ was isolated by repeated serial 70 dilution with the basal medium. The enrichment and isolation were performed at $22^{\circ} \mathrm{C}$.

71 Purity of culture was routinely checked by microscopy and sequencing of the 16S rRNA gene fragments. 
In experiments for phenotypic characterizations, strain $\mathrm{Am} 19^{\mathrm{T}}$ was cultured at $30^{\circ} \mathrm{C}$

in the basal medium unless otherwise specified. Cell morphology was observed with phase-contrast light microscopy. The Gram staining test was conducted with a Gramcolor kit (Merck). Activities of catalase and oxidase were assessed as described previously (Kojima \& Fukui 2016) Effect of temperature on growth was examined by culturing at $0,5,8,10,13,15,18,22$, $25,28,30,32,37$ and $45^{\circ} \mathrm{C}$ in the basal medium. Effect of salt concentration on growth was examined with modified versions of the basal medium, which contained no $\mathrm{MgCl}_{2}$ and varying concentrations of $\mathrm{NaCl}$, ranging from 0 to $1400 \mathrm{mM}$ at $100 \mathrm{mM}$ intervals. For test of $\mathrm{pH}$ effect on growth, media of various $\mathrm{pH}$ prepared as below. From the basal medium, $\mathrm{MgCl}_{2}$ was excluded and bicarbonate concentration was reduced to $1 \mathrm{~g} \mathrm{l}^{-1}$. Depending on the $\mathrm{pH}$ to be tested, the modified media were buffered with $20 \mathrm{mM}$ of MES, MOPS or TAPS. All ingredients were mixed and then sterilized by filtration after $\mathrm{pH}$ adjustment with $\mathrm{NaOH}$ or $\mathrm{HCl}$. The $\mathrm{pH}$ tested and buffering reagents were as follows; $\mathrm{pH} 3.3,3.7,4.2,5.0,5.1,5.6,6.1,6.4,6.6,6.8,7.0$ and 7.2 with MES; $\mathrm{pH}$ 6.4, 7.0, 7.2, 7.4, 7.6, 7.8, 7.9, 8.5 and 8.8 with MOPS; $\mathrm{pH} 8.1,8.2,8.5,8.7$ and 9.1 with TAPS.

91 Utilization of growth substrates was tested with the basal medium, by replacing 
92 thiosulfate with one of the followings (mM; unless otherwise specified); tetrathionate (20),

93 elemental sulfur (0.5 g/l), sulfite (5), sulfide (2), acetate (5), formate (5), succinate (2.5),

94 fumarate (5), isobutyrate (2.5), methanol (5), ethanol (2.5), glucose (2.5), xylose (2.5),

95 maltose (5), arabinose (5), cellobiose (1). Heterotrophic growth was also tested in

96 complex liquid media listed below; Reasoner's 2A broth (R2A) broth, one-tenth-strength

97 R2A, nutrient broth, LB broth Miller and tryptone soya broth. Utilization of electron

98 acceptor was tested under anoxic condition, with the basal medium supplemented with

99 nitrate $(20 \mathrm{mM})$ or nitrite $(5 \mathrm{mM})$.

100

101 Chemotaxonomic characterization

102 For analyses of cellular fatty acids and respiratory quinone, the basal medium

103 was simplified by omitting $\mathrm{MgCl}_{2}$. Strain $\mathrm{Am} 19^{\mathrm{T}}$ was grown in the simplified basal

104 medium at $30^{\circ} \mathrm{C}$. The fatty acid profile was obtained with the Sherlock Microbial

105 Identification System (MIDI) version 6.0 (database; TSBA6). Respiratory quinones were

106 extracted as described previously (Bligh \& Dyer, 1959), and then analyzed with HPLC.

108 Genomic characterization

109 Whole genome sequencing was performed using the platforms of Illumina NextSeq

110 and Nanopore GridION, to obtain short and long reads respectively. The resulting reads 
111 from the platforms were assembled by using Unicycler (Ver 0.4.7). The reconstructed

112 genome sequence was annotated with DFAST (Tanizawa et al., 2018).

A genome-based taxonomic classification was made with reference to the

114 Genome Taxonomy Database (GTDB) (Parks et al., 2018). Taxonomic position in GTDB

115 release 95 was determined by analyzing the genome of strain Am19 ${ }^{\mathrm{T}}$ with GTDB-Tk

116 (Chaumeil et al., 2020).

To estimate genome relatedness between $\mathrm{Am} 19^{\mathrm{T}}$ and its close relatives, values of average nucleotide identity (ANI) and digital DNA-DNA hybridization (dDDH) were calculated, by using tools provided by Kostas lab (http://enve-omics.ce.gatech.edu/) and

120 DSMZ, respectively. In the calculation of dDDH with Genome-to-Genome Distance

121 Calculator (GGDC), the formula 2 was applied (Meier-Kolthoff et al., 2013).

123 Phylogenetic analysis based on the 16S rRNA gene Phylogenetic analysis of the 16S rRNA gene was conducted using MEGA version 11

125 (Tamura et al., 2021). The gene sequence of strain $\mathrm{Am} 19^{\mathrm{T}}$ was aligned with those of type

126 strains in the genus Thiomicrorhabdus, using the MUSCLE algorithm. Sulfuriflexus

127 mobilis aks $1^{\mathrm{T}}$ was included in the analysis as an outgroup. With the resulting alignment, genetic distances were calculated by excluding positions with gaps using the best model 
selected by the model selection tool in MEGA.

\section{$131 \quad$ Results}

Physiological and chemotaxonomic characteristics Cells of strain Am19 $19^{\mathrm{T}}$ were Gram-stain-negative, rod-shaped, non-motile, 0.5$0.8 \mu \mathrm{m}$ in width and $1.1-3.0 \mu \mathrm{m}$ in length. They were catalase-negative and oxidasepositive. Strain $\mathrm{Am} 19^{\mathrm{T}}$ grew at $5-37^{\circ} \mathrm{C}$ with optimum growth at $30^{\circ} \mathrm{C}$. Its growth was observed at $\mathrm{pH}$ range of 5.6-8.5, with optimum growth at $\mathrm{pH}$ 6.6-7.0. In the test of salt concentration, growth was observed in the presence of $1300 \mathrm{mM}$ or lower concentrations of $\mathrm{NaCl}$. Strain $\mathrm{Am} 19^{\mathrm{T}}$ did not require $\mathrm{NaCl}$ for growth. and elemental sulfur. None of the tested organic substrate supported growth of the strain. No heterotrophic growth was observed in the complex media tested. In the

143 presence of thiosulfate, anaerobic growth was not observed in the medium containing

144 nitrate or nitrate as sole electron acceptor. Major components in the cellular fatty acid profile of strain $\mathrm{Am} 19^{\mathrm{T}}$ were 
147 and/or $\left.\mathrm{C}_{18: 1} \omega 6 \mathrm{c} ; 33 \%\right)$ and $\mathrm{C}_{16: 0}(14 \%)$. The other fatty acids detected (>0.1\% of total)

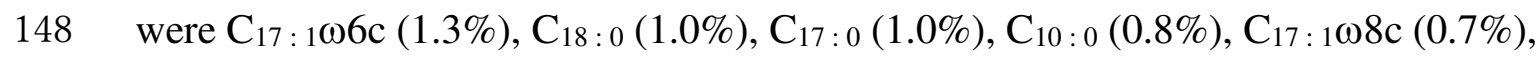

$149 \mathrm{C}_{14: 0}(0.6 \%), \mathrm{C}_{18: 1 \omega 5 \mathrm{c}}(0.5 \%), \mathrm{C}_{10: 0} 3-\mathrm{OH}(0.8 \%), \mathrm{C}_{16: 1} \omega 5 \mathrm{c}(0.3 \%), \mathrm{C}_{12: 0}(0.2 \%)$,

150 summed feature $2\left(\mathrm{C}_{12: 0}\right.$ aldehyde, unknown $10.928, \mathrm{C}_{14: 0} 3-\mathrm{OH}$ and/or iso-C16:1 I;

$1510.2 \%), \mathrm{C}_{15: 1} \omega 6 \mathrm{c}(0.2 \%), \mathrm{C}_{20: 1} \omega 7 \mathrm{c}(0.1 \%)$.

152

In the analysis of quinones, only ubiquinone- 8 was detected.

154 Genomic characteristics and phylogenetic position

The complete genome of strain $\mathrm{Am} 19^{\mathrm{T}}$ was reconstructed from reads of

156 DNBSEQ and GridION. The sequencing coverage was 825.8-fold. The genome consists

157 of a single circular chromosome with size of $2,539,444$ bp and $\mathrm{G}+\mathrm{C}$ contents of $42.7 \%$.

158 In the genome, 2251 protein-coding sequences, 9 rRNA genes and 46 tRNA genes were

159 predicted.

160 The reconstructed genome was analyzed with GTDB-tk, for phylogenetic

161 analysis based on 120 conserved proteins. As a result, strain $A m 19^{\mathrm{T}}$ was classified into

162 the genus Thiomicrorhabdus. On the other hand, the analysis also indicated that strain

163 Am19 ${ }^{\mathrm{T}}$ does not belong to any existing species with validly published name. 
166 threshold for species delineation, 70\% and 95-96\% for dDDH and ANI, respectively

167 (Richter \& Rosselló-Móra, 2009; Meier-Kolthoff et al., 2013).

173 Am $19^{\mathrm{T}}$ belongs to the genus Thiomicrorhabdus but is phylogenetically distinct from existing species.

\section{Conclusions} species but should not be classified into any existing species. Between strain Am19 ${ }^{\mathrm{T}}$ and 
strain $A m 19^{\mathrm{T}}$ and existing species are differentiated by combinations of phenotypic characteristics (Table 2). On the basis of these genomic and phenotypic characteristics,

184 strain $\mathrm{Am} 19^{\mathrm{T}}$ is proposed to be assigned to a novel species of the genus Thiomicrorhabdus, with the name Thiomicrorhabdus immobilis sp. nov.

Description of Thiomicrorhabdus immobilis sp. nov.

Thiomicrorhabdus immobilis (im.mo'bi.lis. L. masc./fem. adj. immobilis, non-motile, pertaining to a feature of the type strain). aerobic. Gram-stain-negative. Catalase-negative and oxidase-positive.

192 Chemolithoautotrophic growth occurs with thiosulfate, tetrathionate, elemental sulfur and sulfide. Acetate, formate, succinate, fumarate, isobutyrate, methanol, ethanol, glucose, xylose, maltose, arabinose and cellobiose are not utilized as growth substrates. Growth of the type strain is observed at temperature range from $5^{\circ} \mathrm{C}$ to $37^{\circ} \mathrm{C}$, with an optimum growth at $30^{\circ} \mathrm{C}$. The $\mathrm{pH}$ range for growth is 5.6-8.5, and the optimum $\mathrm{pH}$ was $6.6-7.0$. The type strain Am19 ${ }^{\mathrm{T}}\left(=\mathrm{NBRC} 114602^{\mathrm{T}}=\mathrm{BCRC} 81336^{\mathrm{T}}\right)$ was isolated from 
accession numbers for the complete of strain $\mathrm{Am} 19^{\mathrm{T}}$ is AP024202.

\section{References}

Boden R, Scott KM, Williams J, Russel S, Antonen K et al. (2017a) An evaluation of Thiomicrospira, Hydrogenovibrio and Thioalkalimicrobium: reclassification of four species of Thiomicrospira to each Thiomicrorhabdus gen. nov. and Hydrogenovibrio, and reclassification of all four species of Thioalkalimicrobium to Thiomicrospira Int J Syst Evol Microbiol 67:1140-1151. https://doi.org/10.1099/ijsem.0.001855

Boden R, Scott KM, Rae AW, Hutt LP (2017b) Reclassification of Thiomicrospira hydrogeniphila (Watsuji et al. 2016) to Thiomicrorhabdus hydrogenophila comb. nov., with emended description of Thiomicrorhabdus (Boden et al., 2017) Int J Syst Evol Microbiol 67:4205-4209. https://doi.org/10.1099/ijsem.0.002279

Bligh EG, Dyer WJ (1959) A rapid method of total lipid extraction and purification. Can J Biochem Physiol 37:911-917. https://doi.org/10.1139/o59-099

Brinkhoff T, Muyzer G, Wirsen CO, Kuever J. (1999a) Thiomicrospira kuenenii sp. nov. and Thiomicrospira frisia sp. nov., two mesophilic obligately chemolithoautotrophic sulfur-oxidizing bacteria isolated from an intertidal mud flat. Int J Syst Bacteriol 49:385-392. https://doi.org/10.1099/00207713-49-2-385 
a mesophilic obligately chemolithoautotrophic sulfur-oxidizing bacterium isolated from a Thioploca mat. Int J Syst Bacteriol 49:875-879. https://doi.org/10.1099/00207713-49-2-875

Chaumeil PA, Mussig AJ, Hugenholtz P, Parks DH (2020) GTDB-Tk: a toolkit to classify genomes with the genome taxonomy database. Bioinformatics 36:1925-1927. https://doi.org/10.1093/bioinformatics/btz848

Kojima H, Fukui M (2016) Sulfuriflexus mobilis gen. nov., sp. nov., a sulfur-oxidizing 3518. https://doi.org/10.1099/ijsem.0.001227

Kojima H, Fukui M (2019) Thiomicrorhabdus aquaedulcis sp. nov., a sulfur-oxidizing https://doi.org/10.1099/ijsem.0.003567

Knittel K, Kuever J, Meyerdierks A, Meinke R, Amann R et al. (2005) Thiomicrospira arctica sp. nov. and Thiomicrospira psychrophila sp. nov., psychrophilic, obligately sediments. Int J Syst Evol Microbiol 55:781-786. https://doi.org/10.1099/ijs.0.63362- 
obligately chemolithoautotrophic, sulfur-oxidizing bacterium isolated from a deephttps://doi.org/10.1099/ijsem.0.003744

Liu X, Chen B, Lai Q, Shao Z, Jiang L (2021) Thiomicrorhabdus sediminis sp. nov. and Thiomicrorhabdus xiamenensis sp. nov., novel sulfur-oxidizing bacteria isolated from coastal sediments and an emended description of the genus Thiomicrorhabdus Int J Syst Evol Microbiol 2021;71:004660. https://doi.org/10.1099/ijsem.0.004660

Meier-Kolthoff JP, Göker M, Klenk H-P (2014) Taxonomic use of DNA G+C content and DNA-DNA hybridization in the genomic age. Int J Syst Evol Microbiol 64:352-356. https://doi.org/10.1099/ijs.0.056994-0

Parks DH, Chuvochina M, Waite DW, Rinke C, Skarshewski A, Chaumeil PA, https://doi.org/10.1038/nbt.4229

Richter M, Rosselló-Móra R (2009) Shifting the genomic gold standard for the prokaryotic species definition. Proc Natl Acad Sci 106:19126-19131. https://doi.org/10.1073/pnas.0906412106 
Analysis version 11. Mol Biol Evol 38:3022-3027.

256 https://doi.org/10.1093/molbev/msab120

257 Tanizawa Y, Fujisawa T, Nakamura Y (2018) DFAST: a flexible prokaryotic genome

258 annotation pipeline for faster genome publication. Bioinformatics 34:1037-1039.

259 https://doi.org/10.1093/bioinformatics/btx713

260 Watsuji TO, Hada E, Miyazaki M, Ichimura M, Takai K (2016) Thiomicrospira

261 hydrogeniphila sp. nov., a novel aerobic, hydrogen-and sulfur-oxidizing

262 chemolithoautotroph isolated from a seawater tank containing a block of beef tallow.

263 Int J Syst Evol Microbiol 66:3688-3693. https://doi.org/10.1099/ijsem.0.001250

264

265 Statements and Declarations

266 The authors declare that no funds, grants, or other support were received during

267 the preparation of this manuscript. The authors have no relevant financial or non-financial

268 interests to disclose. 
Table 1. Values of $\mathrm{dDDH}$ and ANI between strain $\mathrm{Am} 19^{\mathrm{T}}$ and genome-sequenced strains in the genus Thiomicrorhabdus

\begin{tabular}{llc}
\hline Strain (accession number) & dDDH (\%) & ANI (\%) \\
\hline Thiomicrorhabdus sp. Kp2 (GCA_000478585.1) & 21.1 & 80 \\
Thiomicrorhabdus sp. Milos-T2 (GCA_000702325.1) & 20.9 & 80 \\
Thiomicrorhabdus sp. HH3 (GCA_013391695.1) & 15.8 & 79 \\
Thiomicrorhabdus sp. HH1 (GCA_013391765.1) & 16.2 & 78 \\
T. aquaedulcis HaS4 ${ }^{\mathrm{T}}$ (GCA_004001325.1) & 16.2 & 78 \\
T. indica $13-15 \mathrm{~A}^{\mathrm{T}}$ (GCA_004293625.1) & 16.5 & 78 \\
T. sediminis G1 ${ }^{\mathrm{T}}$ (GCA_005885815.1) & 16.8 & 79 \\
T. xiamenensis G2 ${ }^{\mathrm{T}}$ (GCA_013282625) & 16.4 & 79 \\
T. arctica DSM 13458 ${ }^{\mathrm{T}}$ (GCA_000381085.1) & 16.4 & 78 \\
T. chilensis DSM 12352 ${ }^{\mathrm{T}}$ (GCA_000483485.1) & 16.3 & 79 \\
\hline
\end{tabular}


Table 2. Differential properties of strain $\mathrm{Am} 19^{\mathrm{T}}$ and type strains of Thiomicrorhabdus species.

Strains: 1, Am19 ${ }^{\mathrm{T}}$; 2, T. frisia JB-A2 ${ }^{\mathrm{T}}$ (Brinkhoff et al., 1999a); 3, T. chilensis Ch-1 ${ }^{\mathrm{T}}$ (Brinkhoff et al., 1999b); 4, T. arctica SVAL-E (Knittel et al., 2005); 5, T. psychrophila SVAL-D ${ }^{\mathrm{T}}$ (Knittel et al., 2005); 6, T. hydrogeniphila MAS2 ${ }^{\mathrm{T}}$ (Watsuji et al., 2016); 7, T. aquadulcis

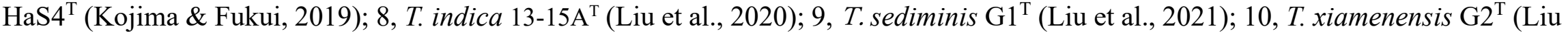
et al., 2021). All strains are obligate chemolithoautotrophs which oxidize thiosulfate, tetrathionate and sulfur. NR, not reported.

\begin{tabular}{|c|c|c|c|c|c|c|c|c|c|c|}
\hline & 1 & 2 & 3 & 4 & 5 & 6 & 7 & 8 & 9 & 10 \\
\hline $\begin{array}{l}\text { Optimum pH for } \\
\text { growth }\end{array}$ & $6.6-7.0$ & 6.5 & 7 & 7.3-8.0 & $7.5-8.5$ & 6 & $6.6-7.4$ & 7 & 7.5 & 6.5 \\
\hline $\mathrm{pH}$ range for growth & $5.6-8.5$ & $4.2-8.5$ & $5.3-8.5$ & $6.5-9.0$ & $6.5-9.0$ & $5.0-8.0$ & $6.2-8.8$ & $5.0-9.0$ & $6.0-9.0$ & $5.5-8.0$ \\
\hline $\begin{array}{l}\text { Optimum temperature } \\
\text { for growth }\left({ }^{\circ} \mathrm{C}\right)\end{array}$ & 30 & $32-35$ & $32-37$ & $11.5-13.2$ & $14.6-15.4$ & 30 & 22 & 28 & 30 & 28 \\
\hline $\begin{array}{l}\text { Temperature range } \\
\text { for growth }\left({ }^{\circ} \mathrm{C}\right)\end{array}$ & $5-37$ & $3.5-39$ & $3.5-42$ & $-2.0-20.8$ & $-2.0-20.8$ & $2-40$ & $0-25$ & $10-45$ & $10-40$ & $4-45$ \\
\hline $\begin{array}{l}\text { Fourth most abundant } \\
\text { fatty acid* }\end{array}$ & $\mathrm{C}_{17: 1}$ & NR & $\mathrm{C}_{18: 0}$ & $\mathrm{C}_{14: 1}$ & $\mathrm{C}_{12: 1}$ & $\mathrm{C}_{12: 0}$ & $\mathrm{C}_{18: 0}$ & $\mathrm{C}_{10: 0} 3-\mathrm{OH}$ & $\mathrm{C}_{18: 0}$ & $\mathrm{C}_{10: 0} 3-\mathrm{OH}$ \\
\hline $\begin{array}{l}16 \mathrm{~S} \text { sequence identity } \\
\text { to strain } \mathrm{Am} 19^{\mathrm{T}}(\%)\end{array}$ & 100 & 97.7 & 96.5 & 97.3 & 96.7 & 97.1 & 95.3 & 94.9 & 96.2 & 94.7 \\
\hline
\end{tabular}

*Following to $\mathrm{C}_{16: 1}, \mathrm{C}_{18: 1}$ and $\mathrm{C}_{16: 0 \text {. }}$ 
Fig. 1 Maximum-likelihood tree showing the phylogenetic position of strain $A m 19^{\mathrm{T}}$ within the genus Thiomicrorhabdus, based on the 16S rRNA gene sequences. A discrete gamma distribution was used to model differences in evolutionary rates among sites. The rate variation model allowed for some sites to be invariable. All positions containing gaps and missing data were eliminated, leaving a total of 1407 positions in the final dataset. Numbers on nodes represent percentage values of 1000 bootstrap resampling.

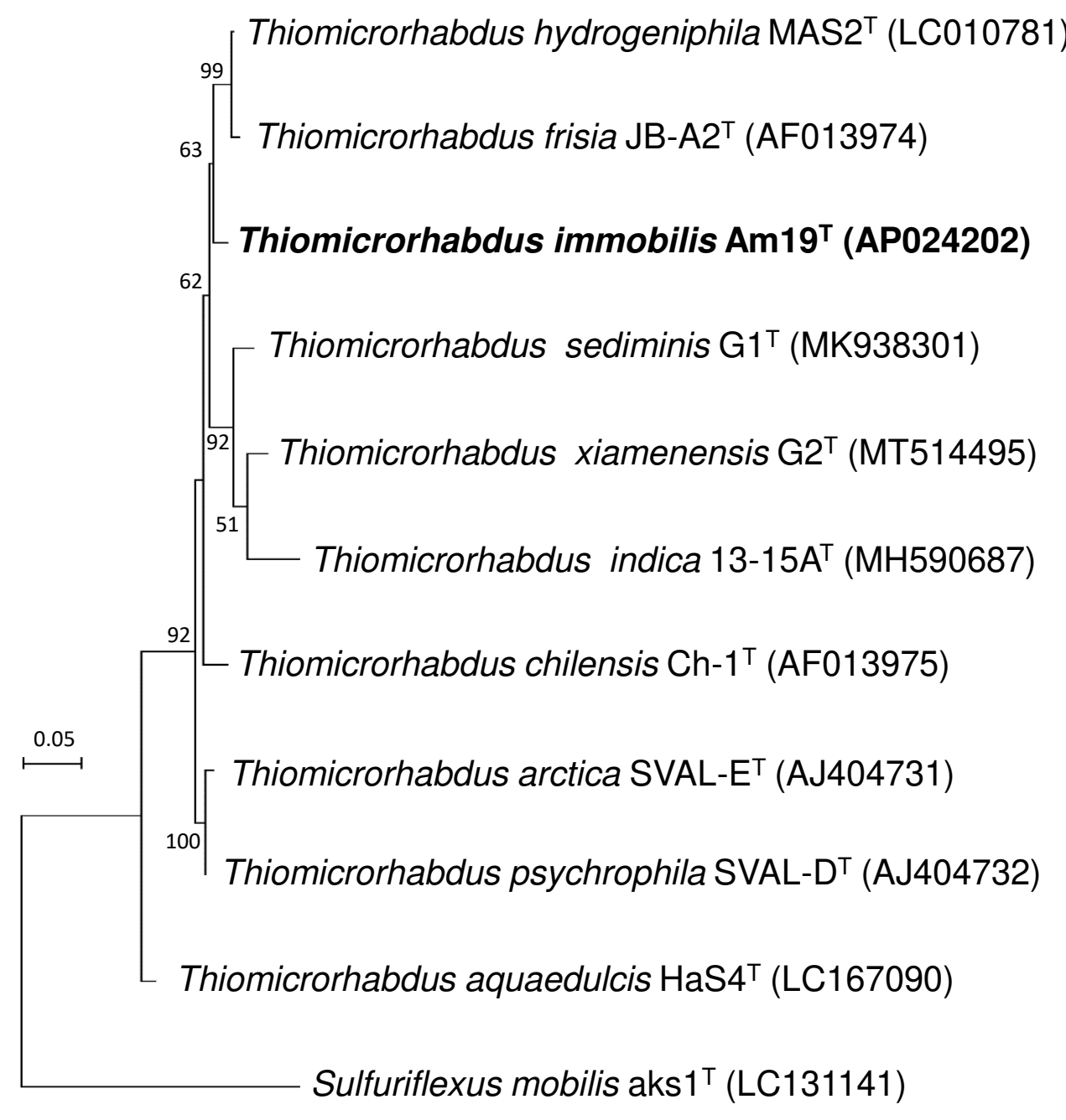

